\title{
Left gastric vein on the dorsal side of the splenic artery: a rare anatomic variant revealed during gastric surgery
}

\author{
Chang-Ming Huang $\cdot$ Jia-Bin Wang $\cdot$ \\ Yi Wang $\cdot$ Chao-Hui Zheng $\cdot$ Ping Li $\cdot$ \\ Jian-Wei Xie $\cdot$ Jian-Xian Lin $\cdot$ Jun Lu
}

Received: 5 April 2013/Accepted: 8 June 2013/Published online: 21 June 2013

(c) The Author(s) 2013. This article is published with open access at Springerlink.com

\begin{abstract}
Purpose The left gastric vein (LGV) is an important blood vessel requiring dissection during gastric surgery. We describe a rare anatomic variant of the LGV.

Methods The LGV drainage pattern was analyzed relative to intraoperative vascular anatomy in 2,111 patients with gastric cancer who underwent radical resection from May 2007 to September 2012. The incidence of the anatomic variant was determined, and the diameter and length of the LGV and the distances from the end of the LGV to the splenoportal confluence and the root of the left gastric artery (LGA) were measured by abdominal CT reconstruction.

Results In 6 of the 2,111 (0.28\%) gastric cancer patients who underwent radical resection, the LGV descended on the left side of the gastropancreatic fold, ran across the dorsal side of the splenic artery and drained into the splenic vein. The mean diameter and length of the LGV were $5.10 \pm 0.40$ and $37.40 \pm 5.19 \mathrm{~mm}$, respectively, and the mean distance from the end of the LGV to the splenoportal confluence was $13.05 \pm 0.86 \mathrm{~mm}$. The closer the LGV and LGA were to the root, the greater the distance between them, with a mean $13.85 \pm 1.02 \mathrm{~mm}$ between the end of the LGV and the root of the LGA.

Conclusions In this rare anatomic variant, the LGV descends along the gastropancreatic fold, runs across the dorsal side of the splenic artery and drains into the splenic vein. Knowledge of this rare anatomic variant will help avoid damage to the LGV during gastric surgery.
\end{abstract}

C.-M. Huang $(\bowtie) \cdot$ J.-B. Wang · Y. Wang · C.-H. Zheng ·

P. Li · J.-W. Xie - J.-X. Lin - J. Lu

Department of Gastric Surgery, Fujian Medical University Union

Hospital, No. 29 Xinquan Road, Fuzhou 350001, Fujian, China

e-mail: hcmlr2002@163.com
Keywords Left gastric vein - Splenic artery $\cdot$ Anatomic variant $\cdot$ Gastric surgery

\section{Introduction}

The left gastric vein (LGV), formerly called the gastric coronary vein, is an important tributary of the portal system. It receives branches from the anterior and posterior sides of the lesser curvature of the stomach, the cardiac region, the lower half of the esophagus, and 1-2 small vessels in the posterior abdominal wall. The LGV, along with the left gastric artery (LGA), runs along the lesser curvature of the stomach, passes through the space between two peritoneal layers of the small omentum, descends along the gastropancreatic fold, and drains into the portal vein (PV) or splenic vein (SV). The drainage patterns of the LGV vary. The LGV usually runs across the dorsal side of the common hepatic artery (CHA) and the ventral side of splenic artery (SA) [21] (Figs. 1, 2), although, in some individuals, the LGV drains directly into the liver [3, 6, 13, 24, 28] (Fig. 3). The LGV may be accidently injured during lymph node dissection in patients with gastric cancer, affecting the circulation and subsequent surgery. Familiarity with the drainage of the LGV, its joining patterns and other related anatomic knowledge is therefore important during radical resection of gastric cancer. During analysis of 2,111 patients who underwent radical resection for gastric cancer, we observed a rare anatomic variant of the LGV.

\section{Materials and methods}

Beginning in May 2007, the Department of Gastric Surgery of the Affiliated Union Hospital of Fujian Medical 


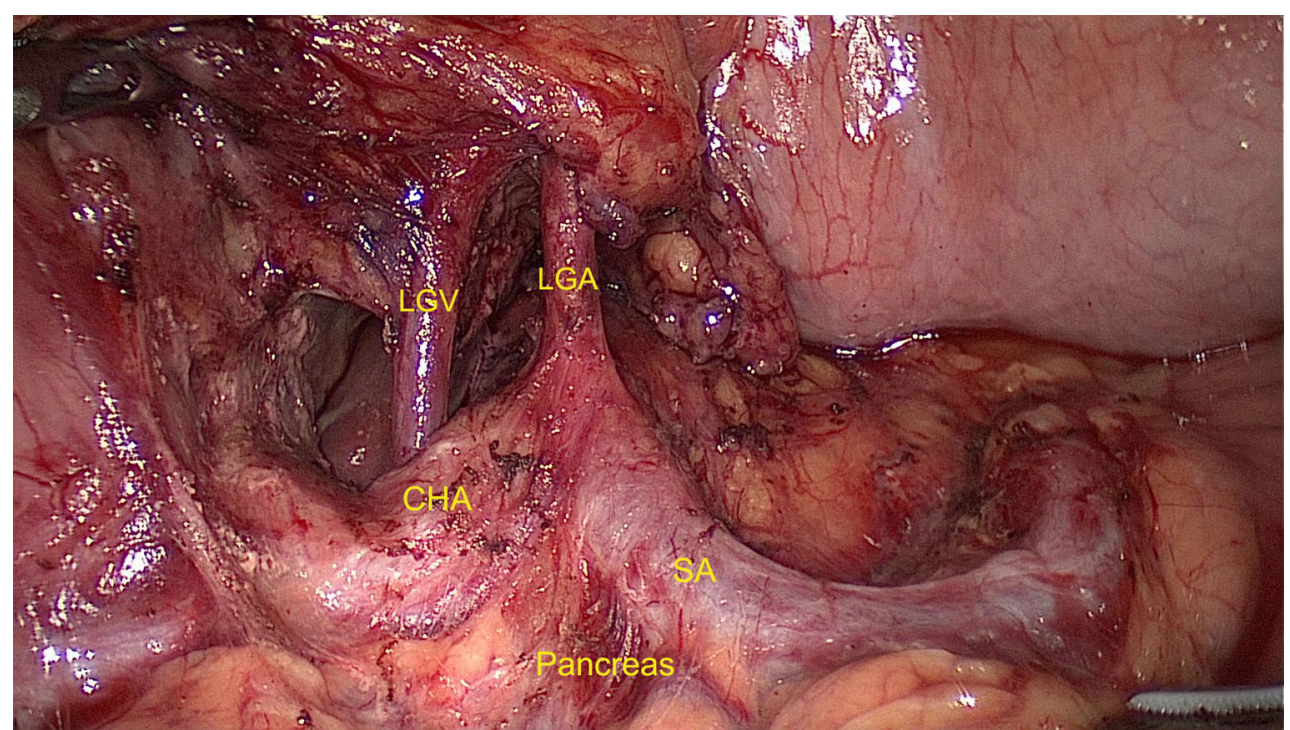

Fig. 1 LGV running across the dorsal side of the common hepatic artery. $L G V$ left gastric vein, $L G A$ left gastric artery, $C H A$ common hepatic artery, $S A$ splenic artery

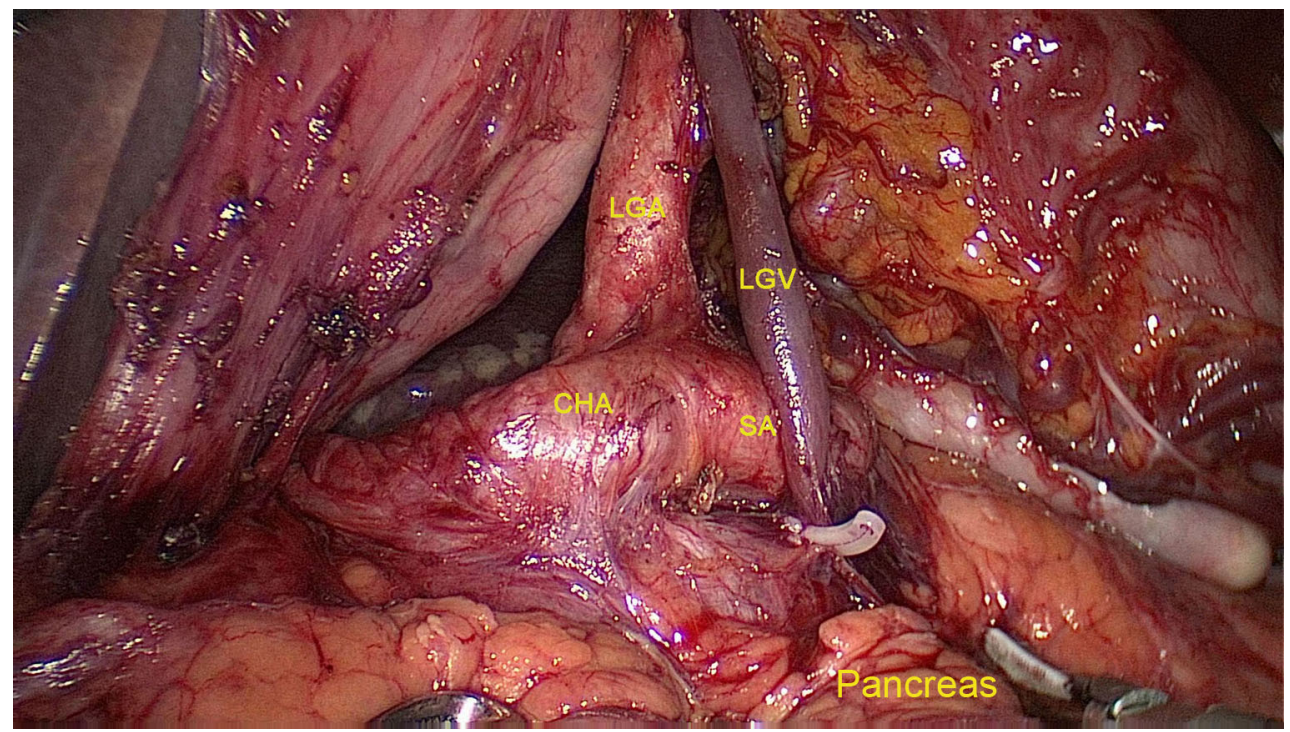

Fig. 2 LGV running across the ventral side of the splenic artery. $L G V$ left gastric vein, $L G A$ left gastric artery, $C H A$ common hepatic artery, $S A$ splenic artery

University established a video database of surgical procedures. By September 2012, the video database included data on 2,111 patients who had undergone radical resection for gastric cancer. The LGV of these patients was anatomically exposed during lymph node dissection. The specific surgical procedure consisted of, first, the assistant holding and tensing the gastropancreatic fold and turning the stomach up. Subsequently, the surgeon gently pressed down the pancreas, exposing its superior border and, using an ultrasonic scalpel, separated the pancreas membrane to reach the posterior pancreas space. The anatomic space at the surface of the SA was separated from left to right to reach the root of the SA. From the root of the SA, the assistant pulled up the lymphatic fatty tissue, which was dissected, and used an ultrasonic scalpel to separate the anatomic space at the surface of the artery. This was followed by dissection of the lymphatic fatty tissue along the celiac artery, exposing the roots of the LGA and LGV. Finally, the surgeon dissected the lymphatic fatty tissue around the LGA and LGV using an ultrasonic scalpel, and skeletoned and cut the LGA and LGV at the superior border of the CHA or SA. Of the 2,111 gastric cancer patients, 6 had the rare anatomic variant of the LGV patients. In six patients, three cases underwent 


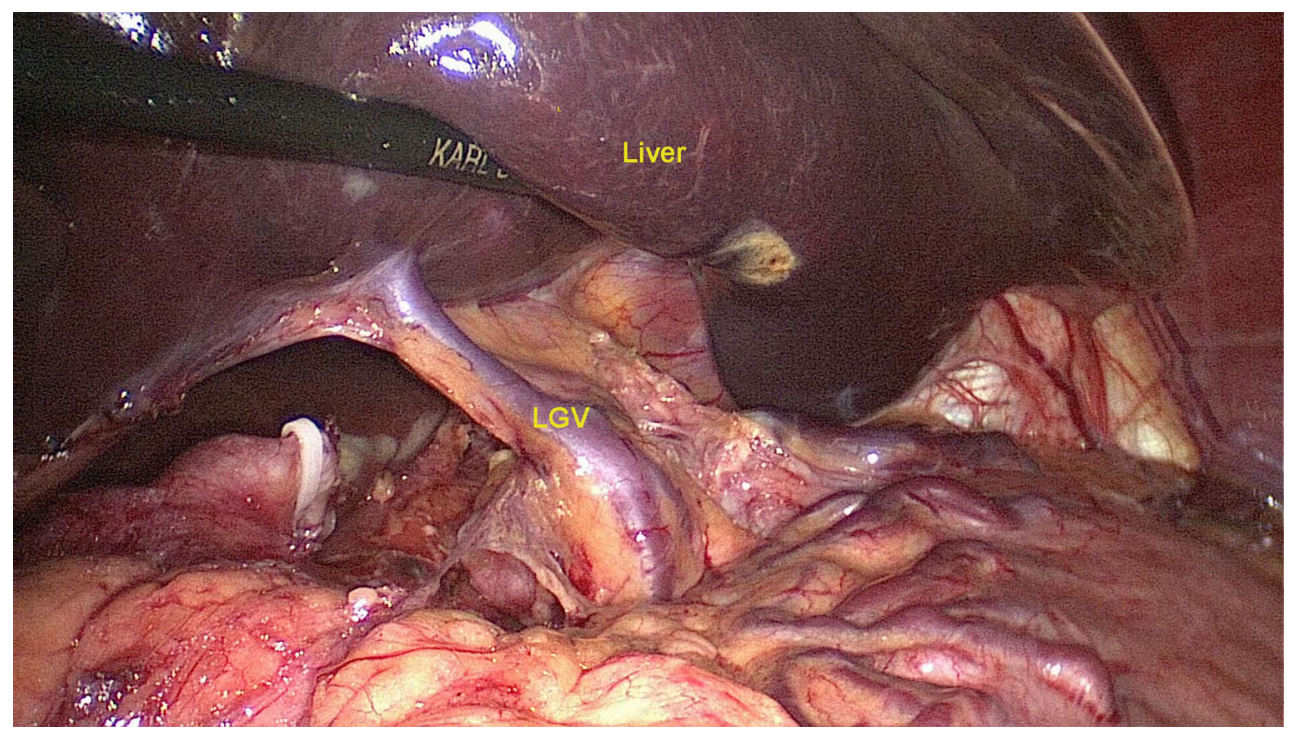

Fig. 3 LGV directly draining into the liver. $L G V$ left gastric vein

laparoscopy-assisted distal gastrectomy and three cases underwent laparoscopy-assisted total gastrectomy. All the operations were undertaken with curative resection (R0) and received a D2 LN dissection according to the Japanese Classification of Gastric Carcinoma, 3rd edition (JCGC 3rd) [10].

The surgical processes and vascular anatomy were documented in all patients by the surgical video and high definition images. Patients underwent abdominal helical CT (Discovery CT750 HD) scanning, from the top of the diaphragm to the lower edge of the liver. The original scanning images were three-dimensionally reconstructed and used to measure the diameter and length of the LGV, and the distances from its end to the splenoportal confluence and the root of the LGA. Written informed consent was obtained from all patients for publication of this report and any accompanying images, and the study was approved by our institutional review board.

\section{Results}

Incidence and drainage pattern of the anatomic variant of the LGV

Of the 2,111 gastric cancer patients who underwent radical resection, 6 had the rare anatomic variant of the LGV patients (Figs. 4, 5, 6, 7); the incidence of this finding was about $0.28 \%$. Its specific drainage pattern differed from that of the normal LGV. In patients with the variant, small vessels from the anterior and posterior walls of the lesser curvature of the stomach drained into the LGV. It lay close to the LGA in the large part of the lesser curvature, descended along the gastropancreatic fold, ran across the dorsal side of the splenic artery and drained into the splenic vein. These vascular anatomies in six patients were documented by the high definition images during laparoscopicassisted radical gastrectomy.

Clinical data on patients with the anatomic variant of the $\mathrm{LGV}$

Of the six patients with the anatomic variant, five were male and one was female; their mean \pm SD age was $64.83 \pm 15.46$ years (range 43-84 years), and mean \pm SD body mass index (BMI) was $21.95 \pm 3.90 \mathrm{~kg} / \mathrm{m}^{2}$. The mean operation time was $160.00 \pm 25.30 \mathrm{~min}$ and the mean intraoperative blood loss was $55.00 \pm 23.45 \mathrm{ml}$. The mean number of lymph nodes dissected was $38.50 \pm 14.92$, and the mean postoperative hospital stay

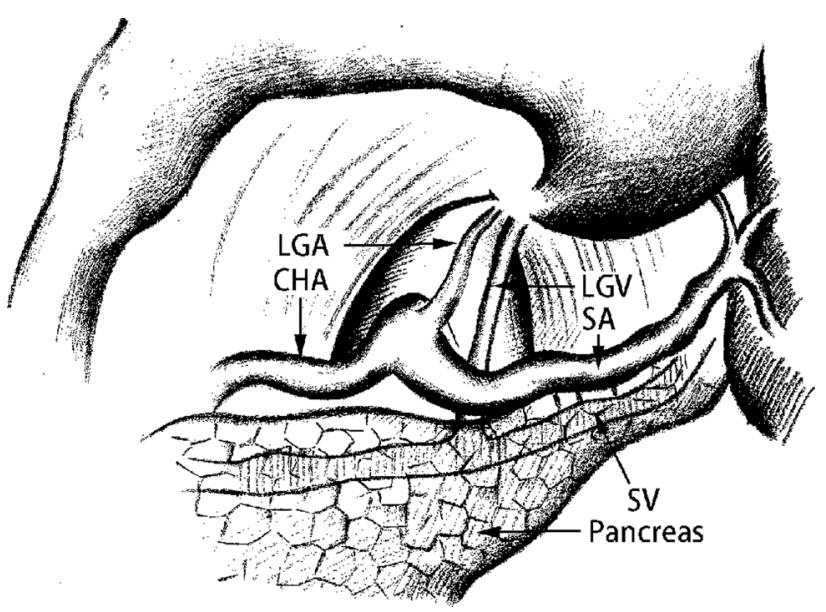

Fig. 4 Schematic drawing of the LGV running across the dorsal side of the splenic artery. $L G V$ left gastric vein, $L G A$ left gastric artery, $C H A$ common hepatic artery, $S A$ splenic artery 


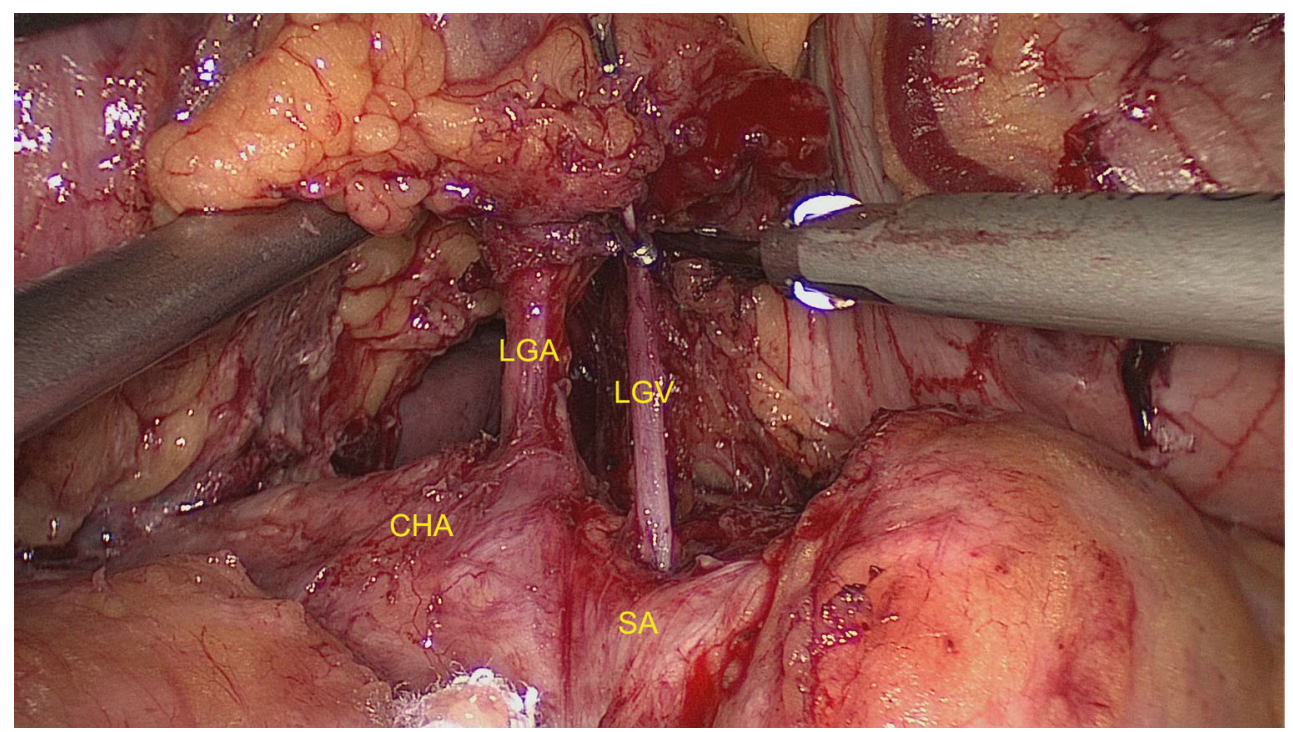

Fig. 5 LGV running across the dorsal side of the splenic artery. $L G V$ left gastric vein, $L G A$ left gastric artery, $C H A$ common hepatic artery, $S A$ splenic artery

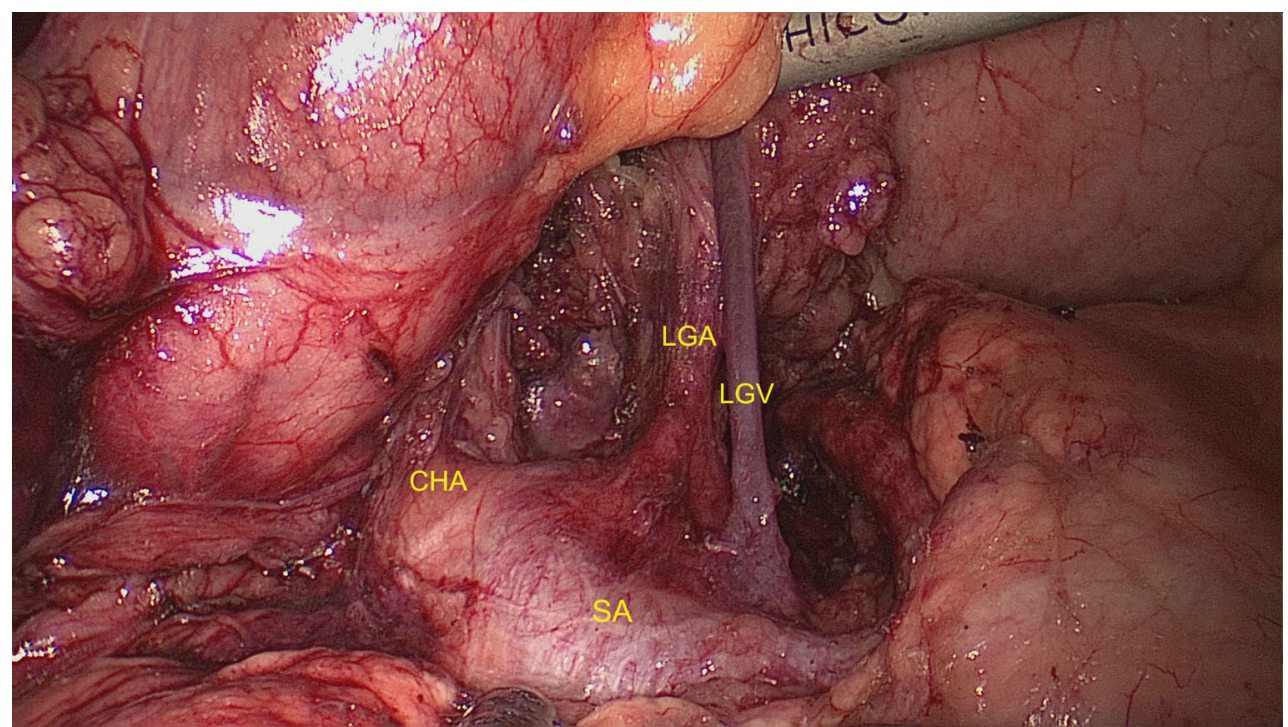

Fig. 6 LGV running across the dorsal side of the splenic artery. $L G V$ left gastric vein, $L G A$ left gastric artery, $C H A$ common hepatic artery, $S A$ splenic artery

was $13.33 \pm 3.67$ days (Table 1$)$. One of these six patients had postoperative morbidity.

\section{Features of the variant LGV}

Using electronic caliper son three-dimensional CT reconstructions (Fig. 8), we measured the diameter and length of each LGV and the distances from its end to the splenoportal confluence and the root of the LGA were measured (Table 2). We found that the mean $\pm \mathrm{SD}$ LGV diameter and length were $5.10 \pm 0.40$ and $37.40 \pm 5.19 \mathrm{~mm}$, respectively, and the mean $\pm \mathrm{SD}$ distance from the end of the LGV to the splenoportal confluence was
$13.05 \pm 0.86 \mathrm{~mm}$. The closer the LGV and LGA were to the root, the greater the distance between them; the mean $\pm \mathrm{SD}$ distance from the end of the LGV to the root of the LGA was $13.85 \pm 1.02 \mathrm{~mm}$. Table 3 shows the mean LGV diameter and length and distances from its end to the splenoportal confluence and the root of the LGA in patients subdivided by age, sex, and BMI.

\section{Discussion}

In most individuals, the LGV starts from small branches of the anterior and posterior walls of the stomach, collects 


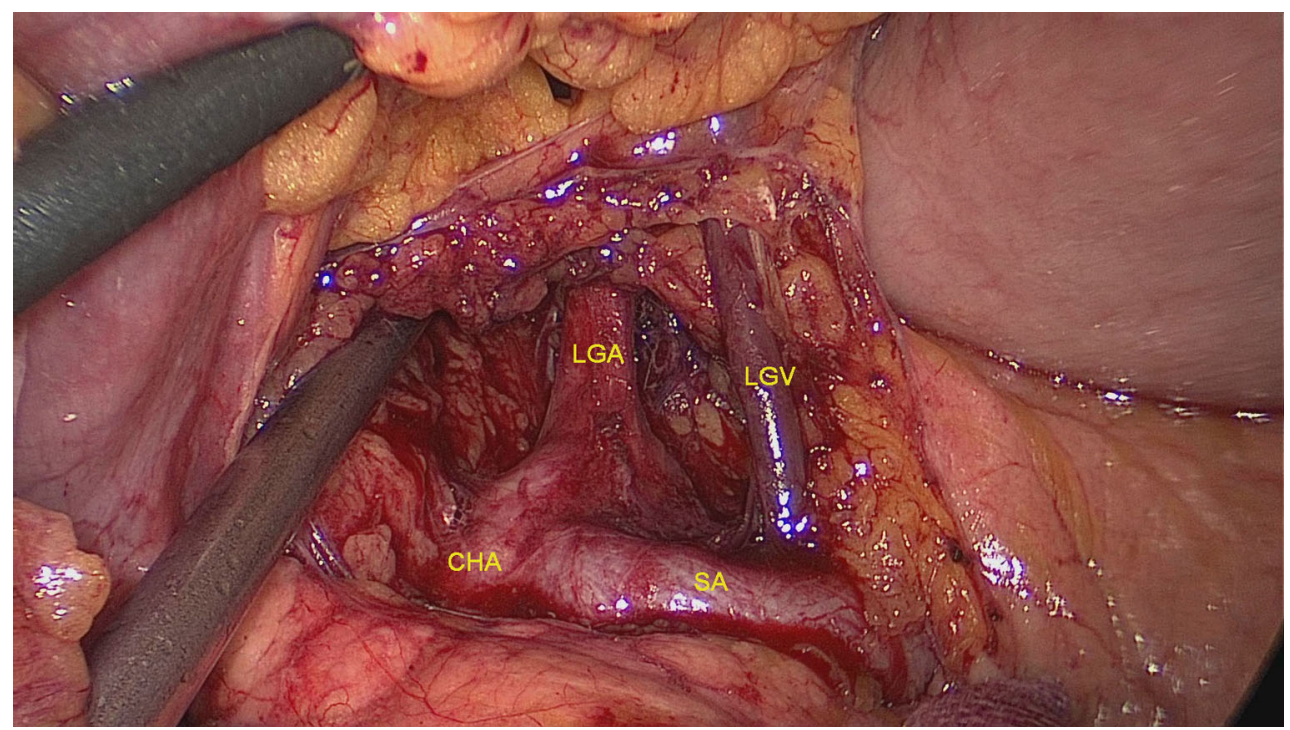

Fig. 7 LGV running across the dorsal side of the splenic artery. $L G V$ left gastric vein, $L G A$ left gastric artery, $C H A$ common hepatic artery, $S A$ splenic artery

Table 1 Clinical data on patients with the variant LGV

\begin{tabular}{lllllllll}
\hline Case no. & Sex & Age (years) & BMI $\left(\mathrm{kg} / \mathrm{m}^{2}\right)$ & $\begin{array}{l}\text { Number of } \\
\text { dissected } \\
\text { lymph } \\
\text { nodes }(n)\end{array}$ & $\begin{array}{l}\text { Operation } \\
\text { time }(\mathrm{min})\end{array}$ & $\begin{array}{l}\text { Blood } \\
\text { loss (ml) }\end{array}$ & $\begin{array}{l}\text { Postoperative } \\
\text { hospital stay } \\
\text { (days) }\end{array}$ & $\begin{array}{l}\text { Postoperative } \\
\text { complications }\end{array}$ \\
\hline 1 & M & 78 & 20.80 & 32 & 180 & 100 & 20 & Pulmonary infection \\
2 & M & 43 & 25.95 & 65 & 120 & 30 & 10 & Not present \\
3 & F & 56 & 26.71 & 47 & 180 & 50 & 14 & Not present \\
4 & M & 71 & 21.30 & 32 & 140 & 50 & 10 & Not present \\
5 & M & 57 & 16.09 & 25 & 160 & 50 & 13 & Not present \\
6 & M & 84 & 20.83 & 30 & 180 & Not present \\
\hline
\end{tabular}

$B M I$ body mass index

blood vessels from the lesser curvature of the stomach, and descends along the gastropancreatic fold. The drainage patterns of the LGV can vary. For example, evaluation of abdominal CT scans in 125 patients showed that, in 49 $(39.2 \%)$, the LGV ran across the dorsal side of the CHA, whereas, in $28(22.4 \%)$, it ran across the ventral side of the SA [22]. In 2 of 245 cadavers $(0.8 \%)$, the LGV entered the liver directly after passing through the hepatogastric ligament [19]. Although there have been several studies of the venous anatomy of the $\operatorname{LGV}[1,4,8,25,27]$, the reasons for the different drainage patterns remain obscure. Embryologically [2, 23], the primitive foregut venous plexus (PFVP) courses along the primitive foregut, while the ductus venosus (DV of Arantius) is anastomosed to the PFVP, resulting in the anastomotic omental veins (AOV). During standard development of the PFVP, the AOV gradually disappear, with both the right and left gastric veins ending in the main PV. Veins, however, must adapt to changes in the intestinal canal and expansion of liver, resulting in different drainage patterns of the LGV probably during the course of evolution. In the rare anatomical variant described here, the LGV ran across the dorsal side of the splenic artery and drained into the splenic vein. This previously undescribed anatomical variant had an incidence of $0.28 \%$.

LGV is one of the most important blood vessels requiring dissection during gastric surgery. Thus, alterations in LGV drainage patterns can affect the surgical process $[16,29]$. Preoperative familiarity with the anatomical features of the LGV is therefore required to avoid accidental dissection of the LGV. Analysis of abdominal CT results of 81 patients showed that the LGV locations could be detected by MDCT preoperatively in 76 patients (93.8\%) [11]. Similarly, we found that LGV locations could be detected by CT reconstruction. Preoperative CT reconstruction in patients with this anatomical variant may provide important reference values for positioning and distinguishing the LGV during surgery for gastric cancer $[12,14,17,18]$. 

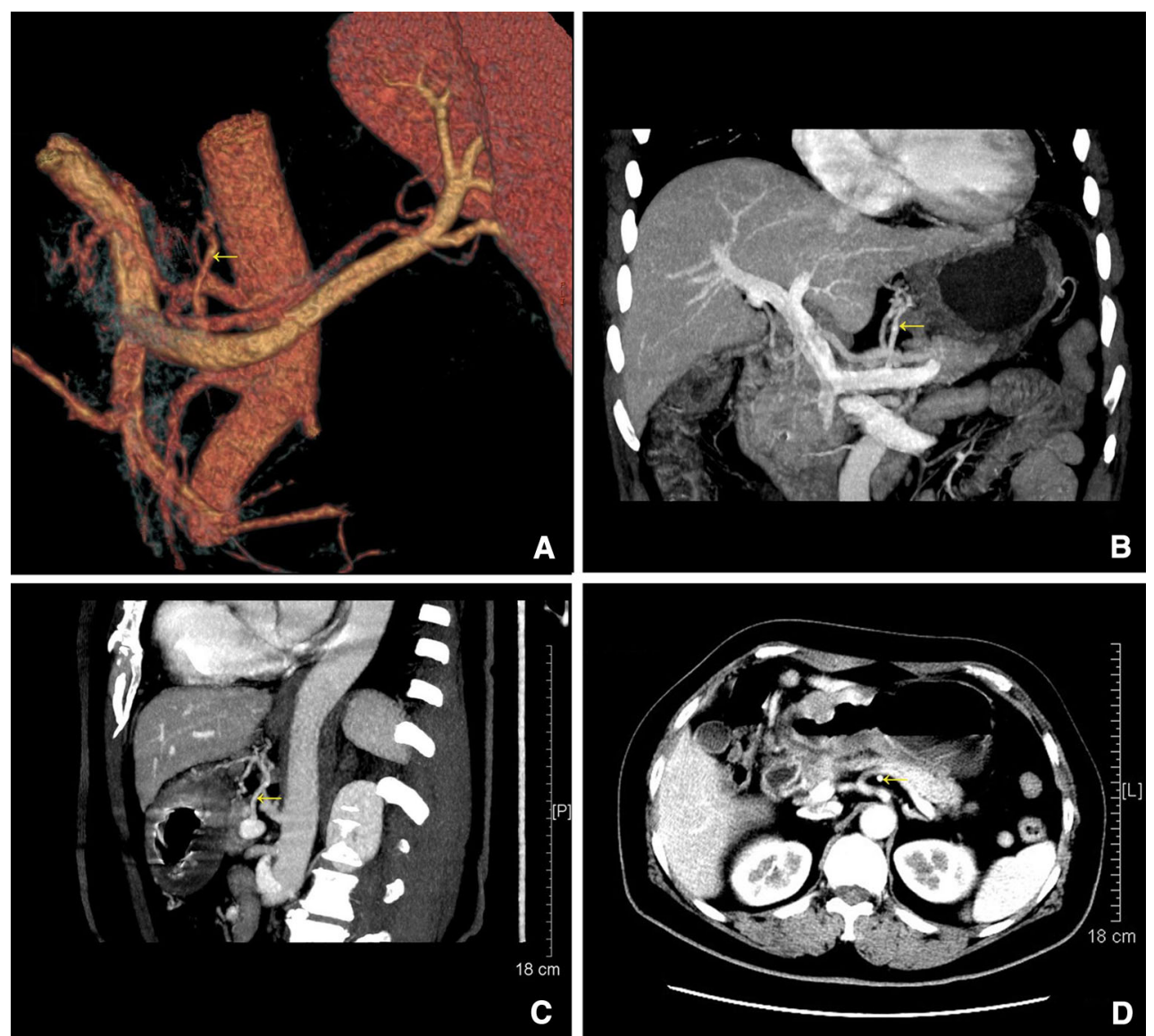

Fig. 8 a-d CT images showing the LGV running across the dorsal side of the splenic artery, and the portion pointed out by arrow refers to the LGV

Table 2 LGV parameters in patient with the variant LGV

\begin{tabular}{lllll}
\hline Case no. & Length of LGV $(\mathrm{mm})$ & $\begin{array}{l}\text { Internal } \\
\text { diameter of } \\
\text { LGV }(\mathrm{mm})\end{array}$ & $\begin{array}{l}\text { Distance from } \\
\text { splenoportal } \\
\text { confluence }(\mathrm{mm})\end{array}$ & $\begin{array}{l}\text { Distance } \\
\text { from root of } \\
\text { LGA (mm) }\end{array}$ \\
\hline 1 & 35.00 & 4.50 & 13.10 & 14.50 \\
2 & 45.00 & 5.60 & 14.60 & 15.10 \\
3 & 39.40 & 5.50 & 12.10 & 14.30 \\
4 & 30.00 & 5.10 & 13.20 & 12.20 \\
5 & 35.00 & 4.90 & 12.80 & 13.30 \\
6 & 40.00 & 5.00 & 12.50 & 13.70 \\
\hline
\end{tabular}

We found that the mean LGV diameter was $5.10 \pm 0.40 \mathrm{~mm}$, the mean LGV length was $37.40 \pm 5.19 \mathrm{~mm}$, and the mean distances from the end of the LGV to the splenoportal confluence and the root of the LGA were $13.05 \pm 0.86$ and $13.85 \pm 1.02 \mathrm{~mm}$, respectively. Although abdominal CT was useful in determining the drainage pattern of the $\operatorname{LGV}[5,7,10,20,26]$, the LGV was small and fragile and could be injured during lymph node dissection in patients with gastric cancer $[9,15]$. Familiarity with the anatomy of LGVs running across the dorsal side of the splenic artery, as well as with adjacent structures, may benefit these patients. Normally, surgeons operating on the region around the superior border of the pancreas should first identify and cut the LGV in the region at the superior border of the CHA or SA, then dissect the lymph nodes. If the LGV is not apparent at the dorsal side of the CHA or the ventral side of the SA, the LGV may drain directly into the liver. If the LGV is undetected while separating the hepatogastric ligament and a single vein is vaguely apparent across the dorsal side of the splenic artery, it may be the anatomic variant described here, with the LGV running across the dorsal side of the splenic artery. Because 
Table 3 Features of LGV running across the dorsal side of the SA

\begin{tabular}{|c|c|c|c|c|c|}
\hline Characteristics & $\begin{array}{l}\text { No. of } \\
\text { patients }\end{array}$ & $\begin{array}{l}\text { Mean length } \\
\text { of LGV (mm) }\end{array}$ & $\begin{array}{l}\text { Mean internal } \\
\text { diameter of } \\
\text { LGV (mm) }\end{array}$ & $\begin{array}{l}\text { Mean distance from } \\
\text { splenoportal } \\
\text { confluence }(\mathrm{mm})\end{array}$ & $\begin{array}{l}\text { Mean distance } \\
\text { from root of } \\
\text { LGA }(\mathrm{mm})\end{array}$ \\
\hline Overall & 6 & $37.40 \pm 5.19$ & $5.10 \pm 0.40$ & $13.05 \pm 0.86$ & $13.85 \pm 1.02$ \\
\hline \multicolumn{6}{|l|}{ Gender } \\
\hline Male & 5 & $37.00 \pm 5.70$ & $5.02 \pm 0.40$ & $13.24 \pm 0.81$ & $13.76 \pm 1.12$ \\
\hline Female & 1 & 39.40 & 5.50 & 12.10 & 14.30 \\
\hline \multicolumn{6}{|l|}{ Age (years) } \\
\hline$\geq 70$ & 3 & $35.00 \pm 5.00$ & $4.87 \pm 0.32$ & $12.93 \pm 0.38$ & $13.47 \pm 1.17$ \\
\hline$<70$ & 3 & $39.80 \pm 5.01$ & $5.33 \pm 0.38$ & $13.17 \pm 1.29$ & $14.23 \pm 0.90$ \\
\hline \multicolumn{6}{|l|}{ BMI $\left(\mathrm{kg} / \mathrm{m}^{2}\right)$} \\
\hline$\geq 25$ & 2 & $42.20 \pm 3.96$ & $5.55 \pm 0.07$ & $13.35 \pm 1.77$ & $14.70 \pm 0.57$ \\
\hline$<25$ & 4 & $35.00 \pm 4.08$ & $4.88 \pm 0.26$ & $12.90 \pm 0.32$ & $13.43 \pm 0.96$ \\
\hline
\end{tabular}

of the rareness of this anatomical variant, it was hard to perceive during surgery. Care should be taken while separating the space on the dorsal side of the splenic artery. If the vein is injured and bleeds, it can affect the course of surgery. Aberrant course of LGV affects the dissection of lymph node during the operation. When an aberrant of LGV is injured during gastric surgery, bleeding and unclear operative field will be caused, thus the difficulty of lymph nodes dissection will increase, which will affect operation procedure, prolong the operation time and increase the complication rate. If the bleeding is improperly handled, it may cause incomplete lymph nodes dissection, intraoperative cancer cells of the metastasis lymph nodes residual and postoperative drop of lymph node metastasis rate, so as to affect the characteristics of oncological resection. In patients with enlarged lymph nodes at the superior border of the pancreas or high $\mathrm{BMI}$, and therefore with relatively more lymphatic fatty tissue surrounding the LGV, it may be relatively difficult to expose the LGV during surgery, increasing the likelihood of damaging the LGV. Care should be taken to identify this anatomic variant preoperatively and to carefully dissect lymphatic fatty tissue at the superior border of the pancreas.

We have described a rare anatomic variant of the $\mathrm{LGV}$, in which the vein descends along the gastropancreatic fold, runs across the dorsal side of the splenic artery and drains into the splenic vein. Preoperative detection of this variant may help avoid damage to the LGV during gastric surgery.

Conflict of interest Drs. Chang-Ming Huang, Jia-Bin Wang, Yi Wang, Chao-Hui Zheng, Ping Li, Jian-Wei Xie, Jian-Xian Lin and Jun Lu have no conflicts of interest or financial ties to disclose.

Open Access This article is distributed under the terms of the Creative Commons Attribution License which permits any use, distribution, and reproduction in any medium, provided the original author(s) and the source are credited.

\section{References}

1. Bergman RA, Thompson SA, Afifi AK et al (1988) Compendium of human anatomic variations. Urban \& Schwarzenberg, Baltimore

2. Broman I (1903) über die existenz eines bisher unbekannten kreislaufes im embyronalen magen. Ann Anz 23:390-391

3. Deneve E, Caty L, Fontaine C, Guillem P (2003) Simultaneous aberrant left and right gastric veins draining directly into the liver. Ann Anat 185:263-266

4. Douglass BE, Baggenstoss AH, Hollinshead WH (1950) The anatomy of the portal vein and its tributaries. Surg Gynecol Obstet 91:562-576

5. Hashi I, Ina H, Hanafusa K, Yoshida T, Himeno Y, Gomi N, Okada Y, Wakita T, Shibuya H, Ohtani S (1997) Aberrant left gastric vein demonstrated by helical CT. J Comput Assist Tomogr 21:996-1000

6. Hans SS, Koukhab M, Hans B (1985) Anterolateral left gastric (coronary) vein: an anatomical variant. Gastrointest Radiol 10(4):347-378

7. Hwang SW, Lee DH, Lee SH, Park YS, Hwang JH, Kim JW, Jung SH, Kim NY, Kim YH, Lee KH, Kim HH, do Park J, Lee HS, Jung HC, Song IS (2009) Preoperative staging of gastric cancer by endoscopic ultrasonography and multidetector-row computed tomography. J Gastroenterol Hepatol 25:512-518

8. Hiwatashi A, Yoshimitsu K, Honda H, Kuroiwa T, Irie H, Tajima T, Jimi M, Chijiiwa K, Masuda K (1999) Pseudo lesion in segment II of the liver observed on CT during arterial portography caused by the aberrant left gastric venous drainage. Abdom Imaging 24:357-359

9. Ibukuro K, Tsukiyama T, Mori K, Inoue Y (1996) Peripancreatic veins on thin-section $(3 \mathrm{~mm})$ helical CT. Am J Roentgenol 167:1003-1008

10. Japanese Gastric Cancer Association (2011) Japanese classification of gastric carcinoma, 3rd English edition. Gastric Cancer 14(2):101-112

11. Kawasaki K, Kanaji S, Kobayashi I, Fujita T, Kominami H, Ueno K, Tsutida S, Ohno M, Ohsawa M, Fujino Y, Tominaga M, Nakamura $T$ (2010) Multidetector computed tomography for preoperative identification of left gastric vein location in patients with gastric cancer. Gastric Cancer 13:25-29

12. Kim HS, Han HY, Choi JA, Park CM, Cha IH, Chung KB, Mok YJ (2001) Preoperative evaluation of gastric cancer: value of spiral CT during gastric arteriography (CTGA). Abdom Imaging 26:123-130 
13. Kubik S, Groscurth P (1977) Eine seltene anomalie der extrahepatischen gallenwege und der V coronaria ventriculi. Chirurg 48:77-80

14. Kumano S, Tsuda T, Tanaka H, Hirata M, Kim T, Murakami T, Sugihara E, Abe H, Yamashita H, Kobayashi N, Mochizuki T (2007) Preoperative evaluation of perigastric vascular anatomy by three-dimensional computed tomographic angiography using 16-channel multidetector-row computed tomography for laparoscopic gastrectomy in patients with early gastric cancer. J Comput Assist Tomogr 31:93-97

15. Lee SW, Shinohara H, Matsuki M, Okuda J, Nomura E, Mabuchi H, Nishiguchi K, Takaori K, Narabayashi I, Tanigawa N (2003) Preoperative simulation of vascular anatomy by three-dimensional computed tomography imaging in laparoscopic gastric cancer surgery. J Am Coll Surg 197(6):927-936

16. Matsuki M, Kani H, Tatsugami F, Yoshikawa S, Narabayashi I, Lee SW, Shinohara H, Nomura E, Tanigawa N (2004) Preoperative assessment of vascular anatomy around the stomach by $3 \mathrm{D}$ imaging using MDCT before laparoscopy-assisted gastrectomy. Am J Roentgenol 183:145-151

17. Matsumoto A, Kitamoto M, Imamura M, Nakanishi T, Ono C, Ito K, Kajiyama G (2001) Three-dimensional portography using multislice helical CT is clinically useful for management of gastric fundic varices. Am J Roentgenol 176:899-905

18. Matsuki M, Tanikake M, Kani H, Tatsugami F, Kanazawa S, Kanamoto T, Inada Y, Yoshikawa S, Narabayashi I, Lee SW, Nomura E, Okuda J, Tanigawa N (2006) Dual-phase 3D CT angiography during a single breath-hold using 16-MDCT: assessment of vascular anatomy before laparoscopic gastrectomy. Am J Roentgenol 186:1079-1085

19. Miyaki T, Yamada M, Kumaki K (1987) Aberrant course of the left gastric vein in the human: possibility of a persistent left portal vein. Acta Anat 130:275-279

20. Mutter D, Marescaux J (2001) Gastrectomies pour cancer: principles généraux, anatomie vasculaire, anatomie lymphatique, curages. Encycl Med Chir 1:40-330-A
21. Natsume T, Shuto K, Yanagawa N, Akai T, Kawahira H, Hayashi $\mathrm{H}$, Matsubara $\mathrm{H}$ (2011) The classification of anatomic variations in the perigastric vessels by dual-phase CT to reduce intraoperative bleeding during laparoscopic gastrectomy. Surg Endosc 25(5):1420-1424

22. Natsume T, Shuto K, Kohno T et al (2010) Anatomic variations of the celiac trunk and the left gastric vein assessing by dualphase CT angiography for safety laparoscopic gastrectomy. J Surg Res 158(2):387-388

23. Nebot-Cegarra J, Domenech-Mateu JM (1984) Ontogenetic study of the hepato gastroesophageal anastomotic omental veins. Acta Anat (Basel) 119:210-216

24. Ohkubo M (2000) Aberrant left gastric vein directly draining into the liver. Clin Anat 13:134-137

25. Roi DJ (1993) Ultrasound anatomy of the left gastric vein. Clin Radiol 47:396-398

26. Ryu KW, Kim YW, Lee JH, Nam BH, Kook MC, Choi IJ, Bae JM (2008) Surgical complications and the risk factors of laparoscopy-assisted distal gastrectomy in early gastric cancer. Ann Surg Oncol 15:1625-1631

27. Matsutani Shoichi, Mizumoto Hideaki (2012) To-and-fro waveforms in the left gastric vein in portal hypertension. J Med Ultrason 39:101-104

28. Tajima H, Murakami R, Kumazaki T (1992) Aberrant left gastric vein directly draining into left portal venous system: a case report. Acta Radiol 33:462-463

29. Takiguchi S, Sekimoto M, Fujiwara Y, Yasuda T, Yano M, Hori M, Murakami T, Nakamura H, Monden M (2004) Laparoscopic lymph node dissection for gastric cancer with intraoperative navigation using three-dimensional angio computed tomography images reconstructed as laparoscopic view. Surg Endosc 18:106-110 